\title{
Art and Science
}

David Peat

\section{Overview of the conference}

On 3-5 March, 1999 a meeting of some fifteen artists and scientists was held at the October Gallery, London. The meeting was sponsored by the Arts Council of England, under the auspices of Bronac Ferran, and was organised by David Peat.

The topic of Art and Science has become quite fashionable of late, with a number of meetings, talks, exhibitions and publications focusing around this general theme. However, most of these tend to be proscriptive with goals, themes, agendas and topics being set before hand. The intention of the October Gallery encounter was to foster a creative atmosphere and conduct an experiment to see just what a highly creative group of artists and scientists would talk about when gathered together in a congenial environment.

Thus the nature of the meeting was discussed on an individual basis with the participants for several weeks before the meeting. In addition, discussion papers were circulated and a discussion group initiated on the Internet. Attention was given to the nature of the meeting place and dinners were taken together. Also, in addition to the artists and scientists, two contact dancers participated. They introduced a somatic awareness into our discussions and, at times, moved the discussion from the purely verbal into physical movement. With respect to comments made at the time, and the interest generated afterwards, the overall experiment must be judged a success.

Most of us met for dinner on March 2, the evening before the meeting, and were therefore able to launch directly into an animated conversation on the following morning. Discussion on the first day ranged over a wide variety of topics as artists and scientists explored each others view points and investigated their different ways of working-several of these topics are mentioned below. While many of the participants found the range of topics stimulating, some felt frustrated at the possible lack of depth. Therefore, on the second morning we focused on two topics -the significance of human consciousness and the need for artists and scientists to create a new type of space for discussion. In the afternoon the meeting split up spontaneously into several small groups to explore individual topics in greater depth.

On the final morning the meeting moved to a different location - a larger room was needed as observers from funding and arts organisations were to join the group towards lunchtime. In retrospect this move was a mistake on the part of the organiser. Over the previous two days the group had developed a considerable sense of solidarity and had discussed the pressures and threats they experienced - from university administrators, funding agencies, dealers, galleries, the market place. Although the change of location had been previously discussed its effect was to break the sense of continuity. In addition, several of the participants felt uncomfortable and even hostile towards the presence of outside observers. But at least this did expose the strong sense of frustration currently being experienced, and shared, by both artists and scientists. It is an issue that should clearly be addressed at any future meeting 


\section{The Connection Between Art and Science}

From the start there was a strong sense that all the participants were on the same side of the fence and that the similarities of their work and sensibility was far greater than their differences. Indeed one of the scientists, Basil Hiley, said that he found it more rewarding to explain his speculative ideas to the artists than with fellow-scientists.

Artists have traditionally drawn on ideas from science and technology but now the transaction also appeared to be taking place in the other direction as well. In several fundamental areas, theoretical physics has reached an impasse and, despite many years of work by top minds in the field, little true progress is being made. It is here that the different reactions, approaches, interests and researches of artists might help. For example, they bring a refreshingly different attitude to issues of matter and space that may help to give scientists an alternative perspective.

As to active collaborations between artists and scientists, it seems that these are best done in individual, idiosyncratic ways and cannot really be planned for or controlled. While many scientists, particularly in the fields of elementary particle and artificial intelligence, and in the human genome project, have learned to work together in large research groups, in general the best scientists, like the best artists, are free spirits who have learned to follow their instincts and enter a particular field because of curiosity and the stimulation it brings, rather than the thought of any external reward. For this reason, things don't seem to work that well when external agencies become involved. They are perceived as being full of aims, goals, agendas and bureaucracy and are not likely to get thanked for their pains! One participant was concerned that there could be too much talk and not enough practical, hands-on action.

There was general agreement that impulses and attitudes are remarkably similar in art and science. Both are motivated by a high degree of intellectual curiosity and, in their respective ways, are constantly asking questions in the pursuit of truth. In particular, scientists urge their students not to accept theories at face value but to look into and question them.

Both artists and scientists felt that their work "came to them", rather than being something they intentionally set out to do. Maybe this is why theories and works of art are defended with such vigour against change and corruption - their origin lies beyond the individual ego or personal history, in something more important than the individual who makes them.

On the other hand much of modern physics, and contemporary art, seems far from everyday life. Science is becoming increasingly abstract and mathematical and, for its part, the general public ignores much contemporary art. Should artists and scientists pay more attention to the relationship between their work and society in general? Should they be concerned with the moral and social values of their work? And to what extent is the need to comment on new ideas and relate them to society the business of art?

In their discoveries, scientists are strongly guided by aesthetic criteria and, in many ways, creating a theory becomes a work of art. On the other hand, as Antony Gormley spoke about his approach to sculpture, it appeared that the very physicality of matter, with its mass, scale and texture was of great significance to some artists. Possibly artists are less prone to abstraction and generalisation than scientists. Another difference may be in artists' attitude towards continuity and art history. Much of art is concerned with a continued dialogue, deconstruction and renewal of the past. This seems to be of far less importance to most 
scientists who have never felt it necessary to read Bacon, Galileo, Copernicus or Newton and may even be painfully ignorant about the writings of Neils Bohr on quantum theory.

On the topic of generalisation, participants heard of Grand Unified Theories and the way that science seeks closure, ultimate theories and all-embracing explanations. Some felt this is a very masculine approach and noted how few women are making significant contributions to the physical sciences. Some participants wondered what a "feminine aspect" of science would look like. It was also pointed out that some aspects of the visual arts have a strongly male approach - these were characterised as big statements, large scale works and the sense of permanence as opposed to subtle suggestions, fleeting appearances and work that is designed to disappear. On the other hand, a case was made for "Neolithic" art of geological duration as an expression of human consciousness.

\section{Consciousness}

Consciousness itself was a theme that kept cropping up during the first and second days. It is an issue that is currently engaging theoretical physicists who feel that their own topic may contain clues to the nature of consciousness. For their part, several of the artists specifically felt that their work was about consciousness itself.

In a certain sense, art and science explore the nature of consciousness, its evolution and transformation. Works of art change the consciousness of those who see them, and in turn, this change of consciousness permeates society in general. Scientific ideas also change the way we see and respond to the world.

The group also inquired how far consciousness extends - into the body, into society as a whole, into nature and right down to the elementary particles and space-time itself? And can a creative act change both consciousness and the nature of the matter it is manipulating? Clearly this is an area in which art and science offer each other mutual stimulation and support.

\section{Values}

The idea that art and science may actually change human consciousness is highly significant. One of the artists even suggested that what art does is to encapsulate and compress our present view of the world and then pass it on, in a symbolic form, to future generations.

But despite such grand conclusions several of the participants urged us to think about immediate values in a world that is becoming increasingly obsessed with pseudo-events and where signs are rapidly replacing the real. What art can be produced in such a society? What significance, what importance, what values can it have? There was also general concern about the way scientific and artistic work is corrupted and comodified by society. One artist felt that changes made to work are akin to a kind of rape.

Some of the artists expressed their frustration at the dislocation between their own work and demands of the market place, galleries, funding agencies and so on. Funding agencies and other institutions were perceived to be over constrictive and unable to cultivate fresh ideas. Others felt that, provided the spoon was long enough, it was possible to sup at the same table - provided one first negotiated a strong contract in favour of the artist. 
Likewise the scientists expressed their anger and frustration at what had been happening within the universities over the last decades - original, creative work was no longer being fostered. In extreme cases the universities were in danger of becoming degree factories administered by accountants!

Some participants felt it was time for us all to take a political, social, moral and ethical stand. We are all leaders in our own fields and should assume the responsibility of leaders in society. Another issue was that scientists should be concerned with the ethics and implications of their work and should not simply disseminate their results wholeheartedly. Likewise, artists should be concerned with the impact of their work on the whole of society.

Not everyone agreed with this position. Some felt that their first duty was to their own subject. While, as members of society, these questions were important, as artists or scientists they were not of primary concern. Following Voltaire's "il fault cultiver notre jardin", they believed that it was more important to pay attention to the excellence of one's own work rather than concern oneself with more global issues.

But in one area there was general agreement. That was for artists and scientists to claim their own space - a space in which to dialogue and in which to work.

\section{Space and meetings}

The consideration of the possession of space led into a general discussion of this and future meetings. All agreed that it had been helpful and important to talk to each other in a free and open way and that this process should continue. One of the artists pointed out that the meeting had made him realise how little artists talked to each other - or if they did it, was only about extraneous matters like real estate and taxes. Not only was it important for artists and scientists to meet and dialogue, but also for artists to talk among themselves. (And what of scientists? Many years ago the physicist David Bohm had suggested a meeting of scientists, not so much to talk about their field of research but about the whole process of doing science, its values and motives.)

Is it possible for these discussions to be continued, and even extended, via the Internet? This would certainly play a significant role but the participants also felt that it was important for people to meet face to face. The key issue was to find and claim a physical space. As one participant put it, "we need a large Victorian house with a cook and housekeeper". There should be a strong sense of continuity with an absolute minimum of bureaucracy involved. People should be invited on the recommendation of other participants rather than having to fulfill a series of criteria.

An extension of this idea was the creation of physical centres in several locations with a variety of real and virtual links such as the Internet, larger meetings and so on. The image of an exoskeleton was used. The general conclusion was that this should be only the first of a series of future meetings and discussions. (Several of the participants intend to have their own one on one meetings.) 


\section{Recommendations}

1. Further meetings should be held - this involves looking for locations and funding

2. A dialogue forum via the Internet should be encouraged

3. This overall discussion should be widened to include more participants. As a first step, a way should be found of disseminating some of this discussion to a wider audience. The three days were audio and videotaped. This material should be made available where needed. In addition, a transcript should be made of some of the key discussions.

\section{Acknowledgment}

I would like to thank Jemma Gascoine-Becker for sending me her own report on the meeting and for the participants who have sent me their comments and reactions.

\section{About the reporter}

David Peat obtained his PhD at Liverpool University and carried out research at Queen's University, Canada and the National Research Council of Canada. His particular interest was in the foundations of quantum theory and he had a long collaboration with David Bohm. In 1996 he moved to a small village in Italy where he continues to write. Peat is the author of some 18 books. His interests include the relationship of physics to psychology, particularly Jungian psychology, and the relationship between art and science. 